\title{
The Cardiovascular and Cerebrovascular Effects on Cognition in Persons with Parkinson's Disease: A Systematic Review of the Literature
}

\author{
Adrianna Carey*, Rebecca Julian*, Katlyn Kristeller*, Peter Leonard*, Sara Palmer*, \\ Laura Krisa \\ Thomas Jefferson University, Philadelphia, USA \\ Email: laura.krisa@jefferson.edu
}

Received 10 February 2015; accepted 10 April 2015; published 14 April 2015

Copyright (C) 2015 by authors and Scientific Research Publishing Inc.

This work is licensed under the Creative Commons Attribution International License (CC BY).

http://creativecommons.org/licenses/by/4.0/

(c) (i) Open Access

\begin{abstract}
Purpose: The purpose of this systematic review of the literature is to examine the cerebrovascular and cardiovascular effects on cognition in persons with Parkinson's disease. Relevance: Physical therapy treatment of persons with Parkinson's disease (PD) has traditionally focused on lessening the impact of disease severity by improving quality of life and functional capacity. Research has shown that quality of life in persons with PD is not only significantly affected by motor symptoms, but also by the presence of defined non-motor symptoms such as cerebrovascular perfusion, cardiovascular dysfunction, and cognitive impairment. This study seeks to determine a causative effect among these non-motor symptoms with the intention to better manage cognitive impairment in persons with PD. Methods: A literature search was conducted utilizing the following databases: Scopus, PubMed, and CINAHL. After evaluating and grading studies using the Downs and Black Checklist, a total of seven studies remained for the final review. Results: Five common domains of cognition emerged throughout the seven studies: executive function, attention, verbal memory and fluency, visual memory, and working memory. Considering the articles reviewed, a relationship between cerebrovascular and cardiovascular deficiency and cognitive impairment in persons with PD was established. Conclusions: Persons with PD and certain cerebrovascular and cardiovascular risk factors, including orthostatic hypotension and systemic hypertension, should be referred to appropriate professionals for comprehensive neuropsychological testing secondary to an increased risk for more severe cognitive deficit.
\end{abstract}

*All authors contributed equally to this work.

How to cite this paper: Carey, A., Julian, R., Kristeller, K., Leonard, P., Palmer, S. and Krisa, L. (2015) The Cardiovascular and Cerebrovascular Effects on Cognition in Persons with Parkinson's Disease: A Systematic Review of the Literature. Advances in Parkinson's Disease, 4, 28-42. http://dx.doi.org/10.4236/apd.2015.42005 


\section{Keywords}

\section{Parkinson's Disease, Cognition, Cardiovascular, Cerebrovascular}

\section{Introduction}

Parkinson's disease (PD) is a progressive, neurodegenerative disease characterized by both motor and non-motor symptoms. According to the Parkinson's disease foundation, 7 to 10 million people live with PD worldwide [1]. In America, 60,000 individuals each year are diagnosed with PD, with men being one and a half times more likely to have PD than women [1]. PD is typically associated with four hallmark motor symptoms: resting tremor, rigidity, bradykinesia, and postural instability [2]. In addition to these motor symptoms, several studies have identified the existence of non-motor symptoms and their impacts on persons with PD [3]-[6]. These nonmotor symptoms can be divided into five categories, including neuropsychiatric, autonomic, sensory, gastrointestinal, and sleep disorders [7]. Research shows that many of these non-motor symptoms persist from diagnosis through the advanced stages of PD. Unfortunately, these symptoms remain untreated by typical PD medical management and can have a profound impact on quality of life (QOL) [3]-[6].

One of the most common neuropsychiatric symptoms seen in persons with PD is cognitive impairment (CI). Hely et al. [5] found that $36 \%$ of the PD population presented with mild cognitive impairment as opposed to $10.7 \%-16.8 \%$ in the general population [5]. CI in persons with PD manifests in numerous ways. Impairments in visuospatial function, working memory, long term memory, internal control of attention (the ability to develop encoding and retrieval strategies efficiently), procedural learning, and executive functions are among some of the cognitive deficits commonly identified in persons with PD [8]. Furthermore, the negative effect of CI on QOL in persons with PD has been reported in many studies [3] [4] [9]. In a study investigating the effects of PD on QOL, it was found that CI was associated with lower ratings on the PDQ-39 QOL scale. In this study, CI was found to be a more significant predictor of QOL than even the hallmark features of PD including speech, tremor, rigidity, hypomemia, bradykinesia, gait, and postural instability [3]. Furthermore, Antonini et al. [4] identified CI as one of the PD non-motor symptoms indicative of disease progression and consequently reduced QOL.

In addition to CI, dysfunction of both the cerebrovascular and cardiovascular systems has also often been associated with PD. In persons with PD, evidence of cerebrovascular disease has been found in postmortem brain examination, radiologic neuroimaging, and clinically symptomatic individuals [10]. In postmortem studies, cerebrovascular lesions such as white matter lesions, old ischemic infarcts, lacunes, and cerebral amyloid angiopathy were found in PD brains [11] [12]. Although similar post-mortem findings have been reported in age-matched controls, it is suspected that these vascular changes may have a significant impact on the presentation of nonmotor symptoms, such as CI, in persons with PD [10] [11]. In late onset PD, clinically symptomatic vascular pathology in the form of minor stroke (in addition to diabetes and ischemic heart disease) resulted in higher Hoehn \& Yahr scores, suggesting that cerebrovascular changes had an effect on PD progression [13]. Finally, several studies have shown that cerebrovascular dysfunction presents in the form of widespread cerebral hypoperfusion in persons with PD [14]-[16]. The presence of these cerebrovascular symptoms and changes in PD has led researchers to consider the potential impact of cerebrovascular disease on persons with PD.

The presence of cardiovascular dysfunction has also been noted in persons with PD. Common cardiovascular symptoms seen in PD include impaired blood pressure regulation, impaired thermoregulation, tachycardia, dyspnea, and peripheral edema [17]. In the PD population, the presence of these cardiovascular symptoms has been associated with higher disability levels [18]. Additionally, studies conducted in the general adult population found cardiovascular risk factors, such as hypertension (HTN) and diabetes [19] as well as cardiovascular symptoms such as orthostatic hypotension $(\mathrm{OH})$, to be associated with cognitive decline [20].

Considering the relationship found between cardiovascular/cerebrovascular dysfunction and CI in otherwise healthy adults, it is thought that this same relationship may also contribute to the increased incidence of cognitive impairment in the PD population. Thus, the purpose of this systematic review of the literature is to determine the cardiovascular/cerebrovascular effects on cognition in persons with PD. With a relationship between $\mathrm{CI}$ and cardiovascular/cerebrovascular dysfunction established, more appropriate medical management can be developed to better treat $\mathrm{CI}$ and thus improve QOL in the PD population. 


\section{Methods}

\subsection{Literature Search and Study Selection}

The following key words were chosen to perform our search: autonomic, cognitive, cognition, cardiovascular, Parkinson, Parkinson's, Parkinson's disease, cerebrovascular, hypoperfusion, and blood pressure. A thorough search was completed in Scopus, PubMed, and CINAHL in July 2014. Studies were limited to those in English that analyzed human subjects. Refer to Appendix A for a more detailed description of search history.

After completing the initial literature search, 522 articles were obtained. Thirty seven articles were selected via title relevance and three were pulled from the references of those articles. Nine were eliminated after being identified as "exact duplicates", bringing the remaining total to 31 articles.

Each member was responsible for reviewing each article's abstract and 20 articles were eliminated after this process, resulting in 11 articles. An auxiliary search was performed by the faculty research advisor, which yielded 4 articles. Two articles were chosen from that search via abstract review, bringing the total full text articles to 13.

Three student members read and graded each article while the faculty research advisor read and graded all articles using the Downs and Black checklist [21]. Two articles were eliminated in this process as they were editorial reviews and four more articles were eliminated secondarily due to a lack of appropriate neuropsychological outcome measures, resulting in 7 final articles [22]-[28].

\subsection{Risk of Bias Assessment}

Risk of bias in each study was assessed using the Downs and Black checklist, which was designed to assess the methodological quality not only of randomized controlled trails but also non-randomized studies [21]. These items address internal validity by ensuring that there is accurate statistical analysis, validity of principal outcome measures, confounding variables, randomization, compliance with interventions, and participant and assessor blinding. The researchers independently extracted data regarding outcome of neuropsychological testing, authors' conclusion, disease severity, demographics and compiled information in results table (see Table 1).

\section{Results}

To aid in the assessment and analysis of the seven studies, a table was compiled listing the major components and characteristics of each study (Figure 1). Four out of seven studies included for analysis stated a significant p-value of less than 0.05 [23] [25] [27] [29]. In three of the seven studies, a p-value for significance was not explicitly stated, however, all p-values reported as significant by the authors were less than 0.05 [22] [24] [28]. The Downs and Black Checklist was used to assess quality of evidence in non-randomized studies [21]. The checklist is composed of 27 questions with a maximum total score of 32. Grade of 1 is given to a "Yes", 0 for "No" or "Unable to determine" for all questions except question five ( $2=$ "Yes", 1 = "Partially", $0=$ "No") and question 27, where a possible five points can be awarded [21]. Refer to Table 1 for a listing of Downs and Black total scores for each article reviewed. Table 2 contains a detailed scoring break-down for each article included in this review. The Downs and Black checklist was chosen for its ability to facilitate a more in-depth discussion regarding validity and applicability of selected, non-randomized studies to the research question. After grading discussions, the majority of studies accepted for review and analysis were cross-sectional or retrospective, cross-sectional design.

Risk of bias was assessed using the Downs \& Black checklist which probes literature for information regarding internal validity including: accurate statistical analyses, validity of main outcome measures, confounding, randomization, interventional compliance, and blinding of assessors \& participants [21].

Synthesis of study results culminated in identification of five major cognitive domains used to report associations of cerebrovascular and/or cardiovascular effects on cognition in persons with PD: executive function, attention, verbal fluency and memory, visual memory, and working memory.

\subsection{Executive Function}

Four studies examined cardiovascular or cerebrovascular effects on executive function in persons with PD [23]-[26]. Through single photon emission computed tomography (SPECT), a direct correlation was revealed 
Table 1. Results table.

\begin{tabular}{|c|c|c|c|c|c|c|c|}
\hline Author & $\begin{array}{c}\text { D \& B } \\
\text { score }\end{array}$ & $\mathbf{n}=$ & $\begin{array}{l}\text { Mean } \\
\text { age }\end{array}$ & $\mathbf{H} \& \mathbf{Y}$ & UPDRS & $\begin{array}{l}\text { Medication } \\
\text { on/off times }\end{array}$ & $\begin{array}{c}\text { Dementia } \\
\text { ratings }\end{array}$ \\
\hline $\begin{array}{c}\text { Allcock } \\
\text { et al. } \\
(2006)\end{array}$ & $13 / 27$ & $\begin{array}{c}\mathrm{N}=175 \\
\\
\mathrm{OH}+ \\
\mathrm{n}=87 \\
(63 \mathrm{M}, 24 \mathrm{~F}) \\
\\
\mathrm{OH}- \\
\mathrm{n}=88 \\
(46 \mathrm{M}, 42 \mathrm{~F})\end{array}$ & $\begin{array}{c}\mathrm{OH}+ \\
72.4 \pm 7.5 \\
\\
\mathrm{OH}- \\
69.2 \pm 8.4\end{array}$ & $\begin{array}{l}\text { Not } \\
\text { reported }\end{array}$ & $\begin{array}{c}\text { Section III: } \\
\text { Total mean } \\
17.75 \\
\\
\mathrm{OH}+\text { mean } \\
18.5 \pm 9.0 \\
\mathrm{OH}-\text { mean } \\
17.0 \pm 12.0\end{array}$ & $\begin{array}{c}\text { OFF } \\
\text { medication } \\
\text { after } \\
\text { midnight } \\
\text { on } \\
\text { assessment } \\
\text { day }\end{array}$ & $\begin{array}{l}\text { Excluded } \\
\text { PD pts } \\
\text { with frank } \\
\text { dementia } \\
\text { according } \\
\text { to } \\
\text { DSM-IV }\end{array}$ \\
\hline
\end{tabular}

$-\mathrm{OH}$ worse scores on sustained attention (digit vigilence test, $\mathrm{p}=0.008$ ); differences persisted when persons with MMSE $<24$ were removed (results not reported) -OH worse scores on visual memory (test of picture recognition, $\mathrm{p}=0.027$ ) Key points:

-Persons with PD and $\mathrm{OH}$ demonstrate deficits in visual memory and attention -Identifies $\mathrm{OH}$ as a prognostic indicator for cognitive deficit $\&$ recommends early neuropsychological assessment

-No significant differences between presence of $\mathrm{OH}$ or postprandial hypotension (PPH) \& ANY of the cognitive or behavioral scores used in persons with PD or PDD

OFF $\quad 11 / 40$<smiles></smiles>

PD

Idiaquez

et al.

(2007)

$\mathrm{n}=40$
$(26 \mathrm{M}, 14 \mathrm{~F})$

PD

$69 \pm 8.2$

Control

Mean
$2.8 \pm$

Section III:

$12 \mathrm{hrs}$
prior to
Control

$\mathrm{n}=30$

(18M, 12F)

$69.0 \pm 6.9$

assessment

(27.5\%) with

dementia

according

to DSM-IV
Jones

et al.

(2014)
$14 / 27$

$\mathrm{n}=341$ $n=341$
$(235 \mathrm{M}, 106 \mathrm{~F})$
$64.7 \pm 10$

Not reported
Section III:

$26.3 \pm 10$

\section{Key points:}

-Persons with PD and dementia report higher incidence of cardiovascular issues -Increased motor symptom severity and older age at PD onset related to severity of cognitive impairment -Cannot completely rule out $\mathrm{OH}$ as a reason for cerebral hypoperfusion resulting in dementia

-All persons with PD performed lowest on tests of processing speed, executive function $\&$ delayed verbal memory -PD $+\mathrm{HTN}=$ worse executive function $(p=0.041) \&$ delayed verbal memory $(\mathrm{p}=0.021)$ scores $-\mathrm{PD}+\mathrm{OH}=$ better executive function scores $(p=0.019)$

\section{Key points:}

-HTN as a comorbidity in persons with PD exerts its own negative impact on executive function $\&$ delayed verbal memory above the deleterious effects of disease progression on cognition

14/87 with dementia according to Korean version of MMSE,

Clinical

Kim $14 / 27$

$\mathrm{n}=25$ $67.5 \pm 9.2$

(14M, 11F)

no CI

12.0

(2012)

$\begin{array}{cc}\mathrm{MCI} & 12.0 \\ \mathrm{n}=48 & \mathrm{MCI} \\ (16 \mathrm{M}, 32 \mathrm{~F}) & 70.0 \pm 6.8 \\ & \\ \text { Dementia } & \text { Dementia } \\ \mathrm{n}=14 & 66.2 \pm 8.1 \\ (5 \mathrm{M}, 9 \mathrm{~F}) & \end{array}$

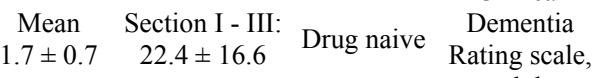
and the sum of the box of the Clinical

Dementia

Rating scale
-All persons with supine HTN (SH) had at least some cognitive dysfunction $(\mathrm{p}<0.001)$

$-\mathrm{OH}+\mathrm{SH}=$ more severe cognitive impairments than those without $\mathrm{OH}$ or $\mathrm{SH}$

Key points:

-All persons with $\mathrm{OH}+\mathrm{SH}$ had some cognitive dysfunction -Frontal executive function negatively related to SD of SBP -Visuospatial memory related to nocturnal BP

-Cognitive impairment related to cerebral perfusion issues like $\mathrm{OH}$ and $\mathrm{SH}$

-Use cognitive tests for early detection of PD and for treatment to slow cognitive decline in persons with PD 


\section{Continued}

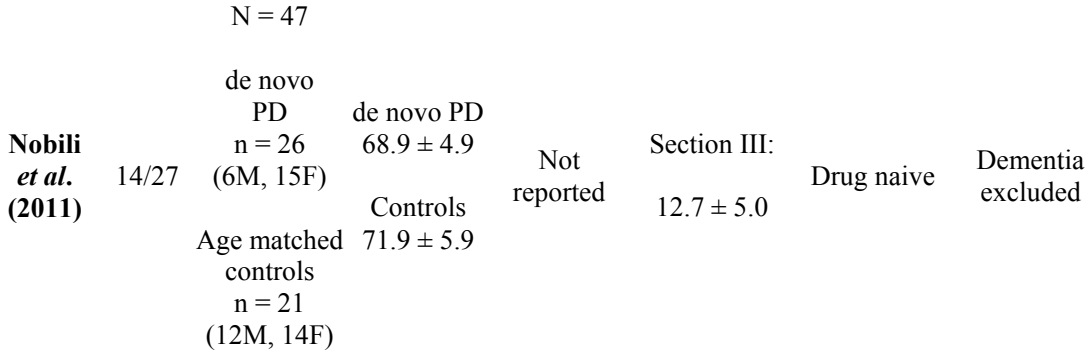

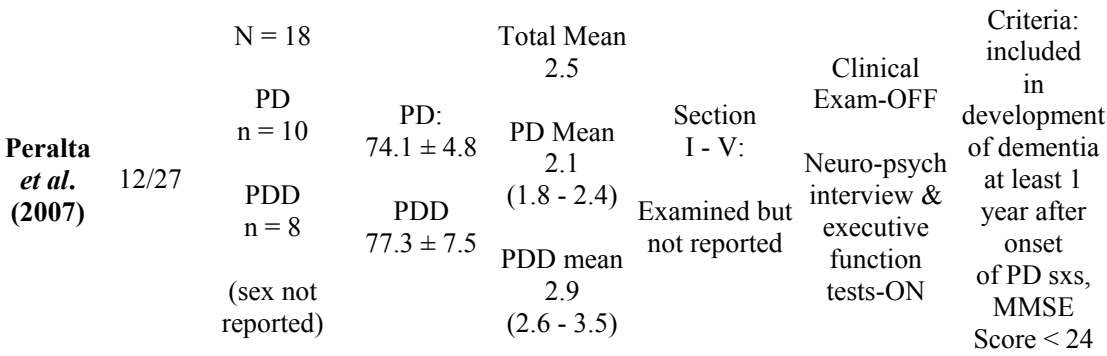
Not administra- reported

-Executive function directly correlated with perfusion in $\mathrm{B} / \mathrm{L}$ posterior cingulate cortex \& $\mathrm{LAH}$ precuneus in de novo (drug naïve) persons with PD -Verbal memory directly correlated with perfusion in precuneus, inferior parietal lobule \& superior temporal gyrus in LAH in de novo persons with PD

\section{Key points:}

-Points to more prominent role of posterior cingulate and parietal cortices in executive dysfunction seen in persons with PD, disputing theory involvement of only frontal lobes in executive dysfunction -Executive function and verbal memory correlated with perfusion in posterior brain areas where dopaminergic nerve endings are less present

-During tilt significant decrease in attention scores for persons with PDD (TEA-2 \& TEA-3; $p<0.005$ )

-During tilt, increase in scores of attention for persons with PD

-During supine, word fluency scores reduced in persons with PDD compared to persons with PD however no significant change of word fluency scores among both groups with OH BP changes -Significant correlation between orthostatic changes in BP \& attention scores in persons with PDD $(p<0.05)$ and persons with PD $(\mathrm{p}<0.05)$

\section{Key points:}

-Correlation between orthostatic BP changes during tilt contributes to theories stating cognitive dysfunction is due to chronic arterial hypotension -Maintaining BP measurements close to normal may improve cognitive functioning in persons with PDD.

-No person with $\mathrm{PD}$ in $\mathrm{OH}-$ group presented with $\mathrm{SH}$

$-\mathrm{OH}+$ group scored lower on sustained attention (AttM; $\mathrm{p}=0.03)$, working memory (Corsi Test; $p=0.004)$, and verbal memory-delayed recall $(\mathrm{RAVLT} ; \mathrm{p}=0.02)$ compared to $\mathrm{OH}-$ group

-Differences in working memory \& verbal memory-delayed recall preserved when persons with MMSE $<24$ were removed from analysis -Both symptomatic \& asymptomatic persons in $\mathrm{OH}+$ group scored similar on all neuropsychological testing

\section{Key points:}

-Relationship between $\mathrm{OH}$ and cognitive deficits that cannot be attributed to cerebrovascular damage (no difference in vascular burden between $\mathrm{OH}^{+}$and $\mathrm{OH}^{-}$groups) 


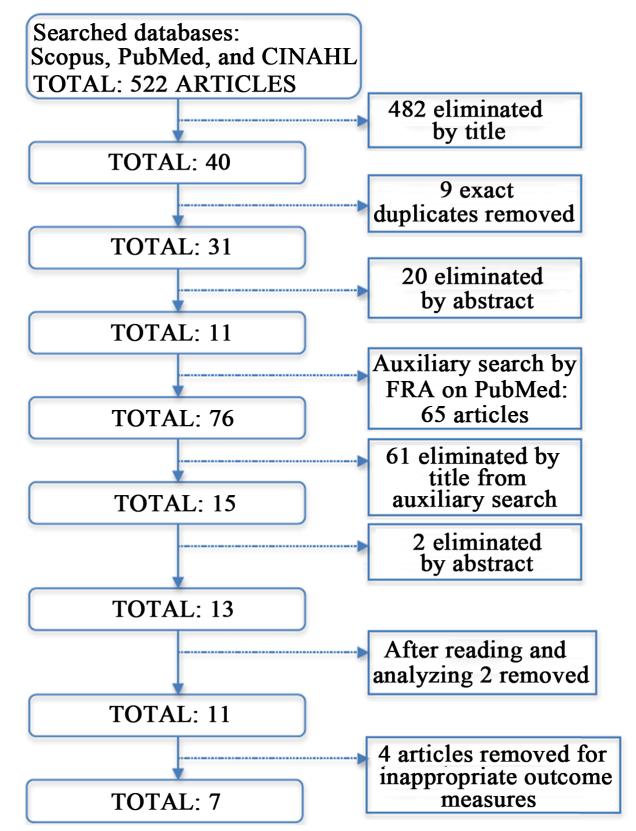

Figure 1. Study selection process.

Table 2. Downs and black checklist scoring.

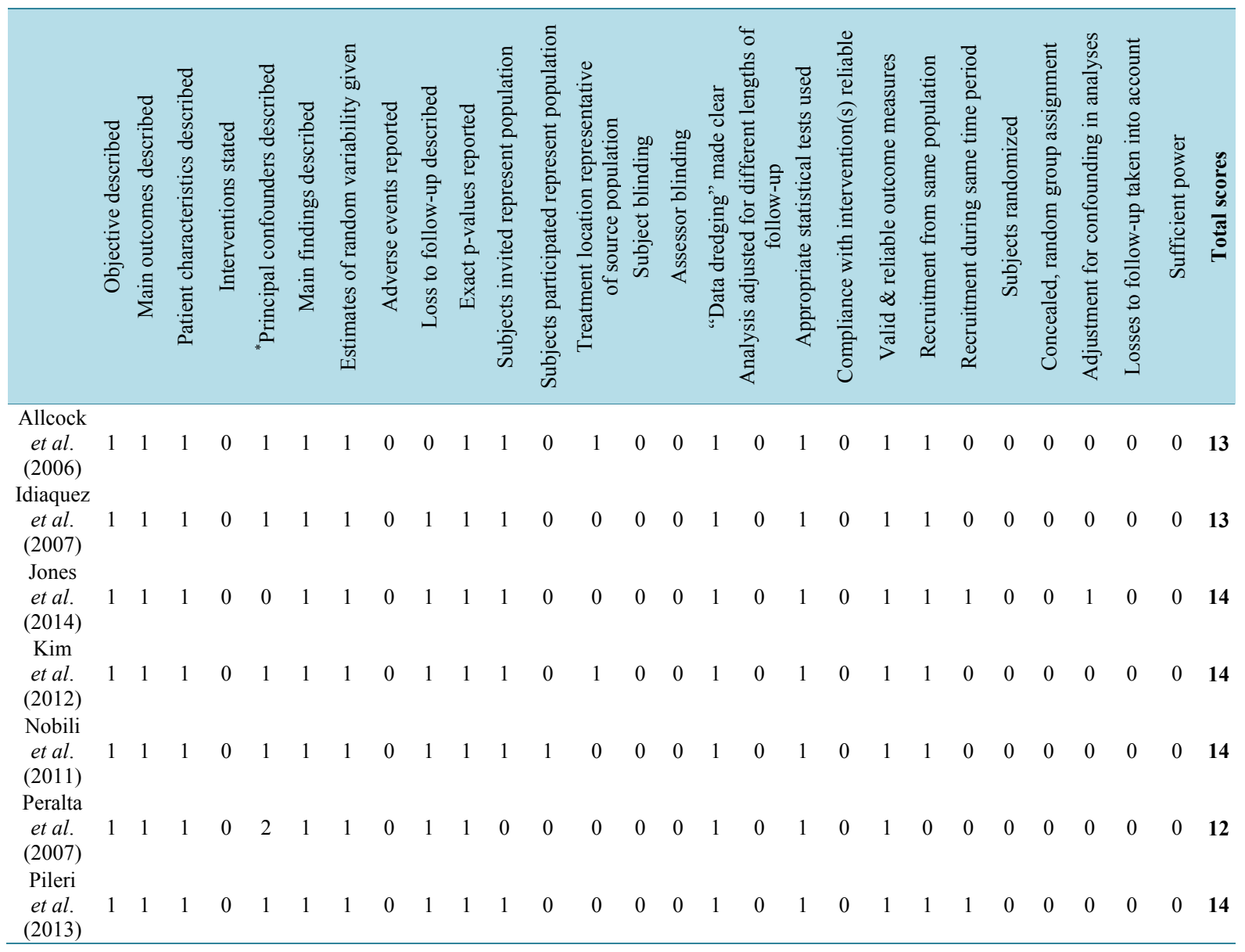

All questions except 1 = Yes; 0 = No/unable to determine. "“Principle Confounders described" 2 = Yes; 1 = Partially; 0 = No. 
between hypoperfusion of the posterior association, limbic, posterior cingulate and parietal precuneus cortices (combined score-p $=0.000$ ) in the less affected hemisphere (ipsilateral hemisphere to side of body with prevalence of motor symptoms) and executive function in persons with PD [26]. This adds support to the presence of a "PD Cognitive Pattern (PDCP)" of hypoperfusion described in previous literature and thought to be correlated with a variety of measures of executive function [26] [30] [31]. A cross-sectional, retrospective study of 341 persons with PD found that the presence of PD and $\mathrm{OH}$, defined as drop in systolic blood pressure $\geq 20 \mathrm{mmHg}$ with postural changes [22]-[24] [27] [28], resulted in better scores on tests of executive function (tests of executive function combined score in PD + OH-p $=0.019$; Trail Making Test-Part B (TMT-B) [32], Stroop Color-Word Test-Golden Version [33], and Controlled Oral Word Association Test (COWAT) [34]) when compared to those with a diagnosis of PD and "health comorbidities in general" (health comorbidities defined as comorbidities that affected at least $10 \%$ of the study population: cholesterol, HTN, hypotension, neurologic, cardiac, arthritis, gastroesophageal reflux disease, cancer, prostate, Roberts syndrome, respiratory, diabetes) (PD + "health comorbidities"-p $=0.146$ ) [24]. The same study also reported the presence of comorbid HTN in persons with PD resulted in decreased scores on tests of executive function (tests of executive function combined score PD + HTN-p $=$ 0.041) compared to persons with PD $+\mathrm{OH}, \mathrm{PD}+\mathrm{OH}+\mathrm{HTN}$, or PD with no other vascular comorbidity [24]. The latter result is supported by Kim et al. [25] who found a negative correlation between executive function scores (COWAT-grocery, $\mathrm{p}<0.05$; COWAT-phonemic, $\mathrm{p}<0.05$; Stroop Word Test, $\mathrm{p}<0.05$ ) and the standard deviation of systolic blood pressure (SBP) (normal cognition group $=13.0 \pm 3.5$, mild cognitive impairment group $=12.8 \pm 2.9$, dementia group $=18.8 \pm 11.1$ ). In contrast to the above studies which reported significant correlations between cardiovascular and/or cerebrovascular dysfunctions and cognitive dysfunctions, Idiaquez et al. [23] reported that the presence of $\mathrm{OH}(\mathrm{p}=0.1)$ or postprandial hypotension $(\mathrm{PPH})(\mathrm{p}=0.4)$ did not significantly affect cognitive or behavioral scores in persons with PD or Parkinson's disease dementia (PDD) (Frontal Assessment Battery (FAB) [35], Blessed Scale [36], Cornell scale for depression [37]).

\subsection{Attention}

Three studies showed a correlation in persons with PD between $\mathrm{OH}$ and lower sustained attention scores (Digit Vigilance Test [38], Test of Everyday Attention subtests 2 and 3 (TEA-2, TEA-3) [39], and the Attentional Matrix (AttM) [22] [27] [28] [40]). Two out of three studies utilized a combination of tilt table and neuropsychological testing to evaluate the connection between $\mathrm{OH}$ and attention [27] [28]. Peralta et al. [27] reported a significant decrease in attentional scores during tilt in all persons with PDD (TEA-2, $\mathrm{p}<0.001$; TEA-3, $\mathrm{p}<0.05$ ) and an upward trend in attentional scores during tilt in all persons with PD (positive change in TEA- $2=0.7 \pm$ 1.1 , TEA-3 $=0.8 \pm 2.1$ ). A significant correlation was also found between the diagnosis of OH with $\mathrm{PD}(\Delta$ diastolic BP (DBP) and TEA-3, $\mathrm{p}<0.05)$ or PDD ( $\triangle$ SBP and TEA-2, $<<0.05 ; \Delta$ DBP and TEA-2, $<<0.05)$ and decreased attention scores [27]. Pilleri et al. [28] used tilt table analysis to diagnose $\mathrm{OH}$, but did not assess cognition during tilt as in Peralta et al. [27]. Despite this difference, their results support findings that persons with $\mathrm{PD}$ and $\mathrm{OH}$ score lower on tests of sustained attention (AttM, $\mathrm{p}=0.03$ ) [28]. It should be noted that when persons with Mini-Mental State Examination (MMSE) $<24$ were excluded, this difference was only a trend towards significance (AttM, $\mathrm{p}=0.05$ ) [28]. Allcock et al. [22] reported similar results regarding $\mathrm{OH}$ and diminished sustained attention score (digit vigilance test, $\mathrm{p}=0.008$ ), however, in contrast to the findings in Pilleri et al. [28], these results were maintained when persons with MMSE $<24$ were excluded from analysis (data not reported).

\subsection{Verbal Memory and Fluency}

Four studies examined the cerebrovascular and/or cardiovascular effects on verbal memory or word fluency in persons with PD [24] [26]-[28]. Using SPECT, a significant correlation was found between cerebral hypoperfusion in the temporoparietal association areas (combined score-p $=0.017$ ) of the cortex in the less affected hemisphere with decreased scores on tests of verbal memory [26]. These results are similar to a previous study of persons with Alzheimer's Disease, a neurodegenerative disease that mimics regional cerebral perfusion maps seen in persons with PDD, which found bilateral temporal perfusion scores were closely correlated to performance of word list learning [26] [41] [42]. Persons with PD and an existing diagnosis of HTN (Hopkins Verbal Learning Test-R [43], form (HVLT-R) and Logical Memory Stories II (WMS-II) [44]; combined score PD + HTN-p $=0.021)[24]$ or OH (Rey Auditory Verbal Learning Test (RAVLT) [45], PD + OHp = 0.02] [28]) were 
also found to have decreased delayed verbal memory recall scores. Decreases in verbal memory recall scores in persons with PD and $\mathrm{OH}$ were maintained when persons with MMSE $<24$ were excluded from statistical analysis (RAVLT, $p=0.03$ ) [28]. The last study in this group reported significantly lower scores of verbal fluency in the supine position for PDD vs. PD alone (Regensburger Verbal Fluency Test [46], between group comparison $p$ $<0.01$ ), however, no significant changes in verbal fluency scores were reported when BP changes consistent with $\mathrm{OH}$ were encountered in both persons with PD alone and PDD ("n.s." = not significant) [27].

\subsection{Visual Memory}

Two studies showed correlations of BP changes in persons with PD and decreased visual memory [22] [25]. One study reported that presence of $\mathrm{OH}$ resulted in lower scores on tests of visual memory (Cognitive Drug Research (CDR) computerized assessment system-test of picture recognition [47], tests of visual memory combined score-p $=0.027$ ) [22]), while the other study reports a relationship between visuospatial function (Rey-Osterrieth Complex Figure Test for non-verbal, visuospatial memory-copy (RCFT-copy) [48], p = -0.040) and changes in nocturnal BP, whereby nocturnal BP increases were associated with worsening cognitive function including visuospatial function [25].

\subsection{Working Memory}

One study cited significantly decreased scores on tests of working memory with the presence of OH in persons with PD (Corsi test [49], $\mathrm{p}=0.004)$ [28]. These results were maintained when persons with MMSE $<24$ were excluded from statistical analysis $(\mathrm{p}=0.003)$.

\section{Discussion}

The primary aim of this review was to determine if there is a clinically significant link between cerebral hypoperfusion, cardiovascular dysfunction, and impaired cognition in persons with PD in order to supplement current diagnostic criteria and symptom management. Disease severity and motor involvement were evaluated in all seven studies using the Unified Parkinson's Disease Rating Scale (UPDRS) and its subscales [22]-[28]. Additionally, five of the seven studies used the Hoehn \& Yahr scale to further measure motor symptom severity [22] [23] [25] [27] [28]. A battery of neuropsychological tests were used to assess different dimensions of cognition, the most common being the MMSE [22] [23] [25]-[28]. The MMSE is a validated test for global cognition in Parkinson's disease [50]. Dubois et al. [50] suggest that while the MMSE is an efficient exam for global cognition, it does not appropriately assess executive function deficits. Age and education level also impact MMSE scores, making it a less reliable tool for the PD population [50]. For these reasons, we eliminated three studies from our review that used MMSE as the primary measure of cognitive function.

This systematic review did not establish a causative correlation between cognitive impairment, brain perfusion, or cardiovascular dysfunction in persons with PD. However, it established that a relationship exists between these variables, the extent of which requires further research. Parkinson's disease is a progressive, degenerative disorder of the central nervous system, therefore, it cannot be determined with certainty whether cognitive impairment is due to altered blood flow to the brain or the ongoing disease process [51] [52]. Nonetheless, $\mathrm{OH}$ has been associated with cognitive decline in dementia, PD, and PDD [52].

$\mathrm{OH}$ is common in persons with $\mathrm{PD}$, with up to $20 \%$ of patients experiencing symptoms [53]. This finding could be attributed to disease progression, dopaminergic drugs, or a failure of the autonomic system [52]. These factors differentiate the presentation of $\mathrm{OH}$ in $\mathrm{PD}$ from the presentation of $\mathrm{OH}$ caused by the ageing process [53]. As orthostasis is a common adverse effect of dopaminergic drugs [10], several of the studies in this review attempted to control for these effects by converting to equivalent doses of standard levodopa [22] [24] [28], restricting medication for 12 hours prior to evaluation [22] [23], examining during "off times" [27], or using a drug-naive population [25] [26]. Overall, the results of the literature reviewed indicate that cognitive test scores were lower in those persons with PD who met the criteria of $\mathrm{OH}$ and/or impaired perfusion. Three studies found a significant correlation between decreased attentional scores and comorbid $\mathrm{OH}$ in persons with PD [22] [27] [28]. That being said, diminished attention scores in persons with PD may be indicative of greater cognitive impairment.

Cerebral hypoperfusion is not the sole perfusion dysfunction impacting cognition in persons with PD. In a study by Kim et al. [25], persons with PD demonstrating supine hypertension ( $\mathrm{SH}$ ), defined as systolic BP $\geq 150$ 
$\mathrm{mmHg}$ or diastolic BP $\geq 90 \mathrm{mmHg}$ in supine, were found to have decreased cognitive function, specifically impaired visuospatial memory. This was overwhelmingly true of those patients who presented with both SH and $\mathrm{OH}$. None of these persons had normal cognition, and they demonstrated the most severe cognitive impairments when compared to the entire study sample [25]. This finding shows that altered cerebral perfusion secondary to $\mathrm{HTN}$ or OH is correlated with decreased cognitive function. Jones et al. [24] found that HTN has an influence on executive function and memory recall that goes beyond the deficits produced by the typical PD disease process. They hypothesized that while these deficits are small, they may become more conspicuous and profound as the disease progresses [24].

Verbal memory has been shown to be involved with the larger, more encompassing memory network, including areas of the brain such as the precuneus, inferior parietal lobe, and superior temporal gyrus [26]. Similar to persons with Alzheimer's dementia, persons with PD demonstrated that a lack of perfusion in the posterior parietal limbic areas and the association areas of the frontal lobe have a negative effect on cognition scores [26]. SPECT scans of persons with PD support this finding, indicating that hypoperfusion affects posterior areas of the brain and results in similar verbal deficits [26].

The same posterior hypoperfusion pattern was found by Derejko et al. [51]. The most identifying feature on SPECT scans of persons with PDD was posterior hypoperfusion, a pattern typically documented in Alzheimer's disease [51]. Additionally, the authors observed marked hyperperfusion of the left thalamus in persons with PDD [51]. Thus, disease-related cognitive decline may not only be due to structural changes in the brain, but also deficits in cardiovascular or cerebrovascular systems [51]. These findings indicate that brain perfusion mapping has the potential to be an indispensable tool for predicting and tracking declining cognitive function in persons with PD [51].

\section{Limitations}

This review had several limitations, the first of which was the lack of standardization for on/off times for dopaminergic medications. As previously stated, all studies attempted to control for pharmacological effects, but the different methods used may have confounded the results. Levodopa (L-dopa) can decrease motor symptoms due to increased synthetic dopamine in the system during "on" times [54]. These motor improvements could affect the disease severity measurements, especially the motor subscale of the UPDRS. Correlations of disease severity and cognitive decline could be confounded if patients were evaluated during L-dopa "on" times versus "off" times. More importantly, BP may be elevated when a patient is in the "off" state and BP may drop to symptomatic levels when the patient is in the "on" state [54]. L-dopa has a known hypotensive effect [55], so if persons with PD were evaluated during "on" times, hypotension might have been a pharmacologic side effect rather than a symptom of cardiovascular dysfunction. This hypotensive effect has been shown to be protective for those with a history of HTN [10], but for the purposes of this review, it may have confounded the results. Blunting HTN with L-dopa could also change the results of studies that found a relationship between HTN and cognition, even if all other HTN medications were controlled [24]. In the future, a standard for testing during on/off times for L-dopa would strengthen results.

The most significant limitation of this review is the inability to distinguish the origin of cognitive decline in persons with PD. Cognitive decline appears to be correlated with later onset and greater severity of motor symptoms [22] [23]. This correlation could be a result of disease progression rather than cardiovascular dysfunction.

For example, widespread Lewy body pathology has been known to cause fluctuating cognition, dementia, and damage to the anterior cingulate cortex (ACC) [22]. In a study by Critchley et al. [56], a direct link between ACC activity and sympathetic output was found. Thus, autonomic dysfunction and altered cognition in persons with PD may perhaps be a result of underlying Lewy body disease (LBD) and not cardiovascular risk factors [57].

A final limitation is the use of drug-naive persons with PD to study cognition [25] [26]. As previously stated, anti-Parkinsonian drugs could affect HTN and consequently cognition [10], therefore, these studies can definitively say their results are not due to adverse effects of L-dopa. However, that advantage may be nullified by the possibility of an inappropriate diagnosis of PD. Quinn [58] described the differential diagnoses for idiopathic $\mathrm{PD}$ and the unfortunate frequency at which PD is misdiagnosed, even by specialists. Without testing for the response to L-dopa, these drug naive populations could potentially be showing signs of LBD or other Parkinsonian syndromes. Kim et al. [25] stated that their sampled population may fall on the continuum between LBD and PD, thus, these results may not be attributable to PD alone. 


\section{Conclusion}

Having established that impaired perfusion negatively impacts cognitive function, it can be inferred that those persons with PD who also have altered BP will display cognitive impairments. It is the contention of this literature review that persons with PD and co-morbid cerebrovascular or cardiovascular impairments will benefit from early cognitive screening with an appropriate neuropsychological testing battery. Early testing would allow for more appropriate interventions with the intention of slowing or monitoring cognitive decline.

\section{Clinical Bottom Line}

With a relationship between cerebrovascular and cardiovascular dysfunction and cognition established, appropriate management of cognition in persons with PD can be more thoroughly considered. Knowing that this relationship exists, the identification of cardiovascular risk factors, such as OH and HTN, can be utilized to warrant further neuropsychological testing. Currently, in persons with PD the MMSE is utilized as the primary measure for neuropsychological screening [50]. However, recent literature suggests that this test is not accurately able to identify cognitive impairment in persons with PD [59]. In a study by Burdick et al. [59], it was found that more than half of persons with PD who scored above normal on the MMSE, also scored below normal on the Montreal Cognitive Assessment. Sixty-seven percent of those with normal MMSE scored 1.5 standard deviations below normal in at least 1 other cognitive test. Sixty-four percent of persons with PD deemed cognitively normal by the MMSE scored 1.0 SD below normal on at least 2 other cognitive measures. Furthermore, this study concluded that if the MMSE were to be the only test utilized to detect dementia in persons with PD, then as many as $55 \%$ of dementia cases would have gone undetected in this population [59]. Thus, considering the prevalence of cognitive impairment and its impact on quality of life in persons with $\mathrm{PD}$, it is imperative that appropriate neuropsychological testing be utilized to aide in early detection of cognitive impairment, especially in cases of individuals with previously identified risk factors.

With risk factors identified and appropriate neuropsychological testing instituted, further management of cognitive impairment in persons with PD can be explored. In a study by Hohler et al. [60], conservative management of $\mathrm{OH}$ in the form of anti-hypertensive medications, maintaining adequate hydration, increasing salt intake, and wearing compression stockings resulted in improvements in the cognitive component of the Functional Independence Measure. In addition to these conservative techniques, other studies have researched the effects of physical activity in treating cognitive impairment in persons with PD. In a study by Ridgel et al. [61], the effects of passive leg cycling on cognition were studied over the course of four exercise sessions. Following bouts of passive leg cycling, no improvements were noted in visual search or motor speeds, however, passive cycling was found to improve set-shifting, a component of executive functioning (as identified by the Trail Making Test A and B) [61].

In another study by Tanaka et al. [62] the effects of a multimodal exercise session on executive function was studied in the PD population. Significant improvements were found in executive function in the training group over the control group (as identified by the Wisconsin Card Sorting Test [63]). Specifically, improvements in abstraction and mental flexibility were noted [62]. Both of these studies hypothesize that physical activity may be able to positively impact the circulatory system in such a way that executive function is consequently improved [61] [62]. Ridgel et al. [61], suggest that the physiologic effects typically associated with exercise (increased cardiac output, stroke volume, heart rate, decreased vagal tone) may function to treat the cardiovascular risk factors identified to affect cognition in person with PD. Likewise, Tanaka et al. [62] hypothesized that exercise in persons with PD may result in increased blood flow to the brain, thus, treating the cerebrovascular perfusion deficits associated with altered cognition in this population. Further research, including detailed imaging in the form of perfusion scans during physical activity, may be warranted in order to better support the aforementioned hypothesis that cognitive impairment in PD can be directly treated by the altered circulation and perfusion patterns identified following exercise. With this information determined, the inclusion of health care professionals such as physical therapists will become instrumental in the treatment of cognitive impairment in persons with PD.

\section{References}

[1] Parkinson's Disease Foundation (2014) Statistics on Parkinson's. http://www.pdf.org/en/parkinson_statistics 
[2] Umphred, D.A., Lazaro, R.T., Roller, M.L. and Burton, G.U. (2013) Umphred's Neurological Rehabilitation. 6th Edition, Elsevier Mosby, St. Louis.

[3] Schrag, A., Jahanshahi, M. and Quinn, N. (2000) What Contributes to Quality of Life in Patients with Parkinson's Disease? Journal of Neurology, Neurosurgery, and Psychiatry, 69, 308-312. http://dx.doi.org/10.1136/jnnp.69.3.308

[4] Antonini, A., Barone, P., Marconi, R., Morgante, L., Zappulla, S., Pontieri, F.E., et al. (2012) The Progression of NonMotor Symptoms in Parkinson's Disease and Their Contribution to Motor Disability and Quality of Life. Journal of Neurology, 259, 2621-2631. http://dx.doi.org/10.1007/s00415-012-6557-8

[5] Hely, M.A., Morris, J.G., Reid, W.G. and Trafficante, R. (2005) Sydney Multicenter Study of Parkinson's Disease: Non-L-Dopa-Responsive Problems Dominate at 15 Years. Movement Disorders, 20, 190-199. http://dx.doi.org/10.1002/mds.20324

[6] Global Parkinson's Disease Survey Steering Committee (2002) Factors Impacting on Quality of Life in Parkinson's Disease: Results from an International Survey. Movement Disorders, 17, 60-67. http://dx.doi.org/10.1002/mds.10010

[7] Chaudhuri, K.R., Yates, L. and Martinez-Martin, P. (2005) The Non-Motor Symptom Complex of Parkinson's Disease: a Comprehensive Assessment Is Essential. Current Neurology and Neuroscience Reports, 5, 275-283. http://dx.doi.org/10.1007/s11910-005-0072-6

[8] Dubois, B. and Pillon, B. (1996) Cognitive Deficits in Parkinson's Disease. Journal of Neurology, 244, 2-8. http://dx.doi.org/10.1007/PL00007725

[9] Barone, P., Antonini, A., Colosimo, C., Marconi, R., Morgante, L., Avarello, T.P., et al. (2009) The PRIAMO Study: A Multicenter Assessment of Nonmotor Symptoms and Their Impact on Quality of Life in Parkinson's Disease. Movement Disorders, 24, 1641-1649. http://dx.doi.org/10.1002/mds.22643

[10] Nanhoe-Mahabier, W., de Laat, K.F., Visser, J.E., Zijlmans, J., de Leeuw, F.E. and Bloem, B.R. (2009) Parkinson's Disease and Comorbid Cerebrovascular Disease. Nature Reviews Neurology, 5, 533-541. http://dx.doi.org/10.1038/nrneurol.2009.136

[11] Jellinger, K.A. (2003) Prevalence of Cerebrovascular Lesions in Parkinson's Disease: A Postmortem Study. Acta Neuropathologica, 105, 415-419.

[12] Mastaglia, F.L., Johnsen, R.D. and Kakulas, B.A. (2002) Prevalence of Stroke in Parkinson's Disease: A Postmortem Study. Movement Disorders, 17, 772-774. http://dx.doi.org/10.1002/mds.10199

[13] Papapetropoulos, S., Ellul, J., Argyriou, A., Talelli, P., Chroni, E. and Papapetropoulos, T. (2004) The Effect of Vascular Disease on Late Onset Parkinson's Disease. European Journal of Neurology, 11, 231-235. http://dx.doi.org/10.1046/j.1468-1331.2003.00748.x

[14] Le Heron, C.J., Wright, S.L., Melzer, T.R., Myall, D.J., MacAskill, M.R., Livingston, L., et al. (2014) Comparing Cerebral Perfusion in Alzheimer's Disease and Parkinson's Disease Dementia: An ASL-MRI Study. Journal of Cerebral Blood Flow \& Metabolism, 34, 964-970. http://dx.doi.org/10.1038/jcbfm.2014.40

[15] Melzer, T.R., Watts, R., MacAskill, M.R., Pearson, J.F., Rueger, S., Pitcher, T.L., et al. (2011) Arterial Spin Labelling Reveals an Abnormal Cerebral Perfusion Pattern in Parkinson's Disease. Brain, 134, 845-855. http://dx.doi.org/10.1093/brain/awq377

[16] Borghammer, P., Chakravarty, M., Jonsdottir, K.Y., Sato, N., Matsuda, H., Ito, K., et al. (2010) Cortical Hypometabolism and Hypoperfusion in Parkinson's Disease Is Extensive: Probably Even at Early Disease Stages. Brain Structure and Function, 214, 303-317. http://dx.doi.org/10.1007/s00429-010-0246-0

[17] Bayulkem, K. and Lopez, G. (2010) Nonmotor Fluctuations in Parkinson's Disease: Clinical Spectrum and Classification. Journal of the Neurological Sciences, 289, 89-92. http://dx.doi.org/10.1016/j.jns.2009.08.022

[18] Raggi, A., Leonardi, M., Carella, F., Soliveri, P., Albanese, A. and Romito, L.M. (2011) Impact of Nonmotor Symptoms on Disability in Patients with Parkinson's Disease. International Journal of Rehabilitation Research, 34, $316-320$. http://dx.doi.org/10.1097/MRR.0b013e32834d4b66

[19] Knopman, D., Boland, L.L., Mosley, T., Howard, G., Liao, D., Szklo, M., et al. (2001) Cardiovascular Risk Factors and Cognitive Decline in Middle-Aged Adults. Neurology, 56, 42-48. http://dx.doi.org/10.1212/WNL.56.1.42

[20] Rose, K.M., Couper, D., Eigenbrodt, M.L., Mosley, T.H., Sharrett, A.R. and Gottesman, R.F. (2010) Orthostatic Hypotension and Cognitive Function: The Atherosclerosis Risk in Communities Study. Neuroepidemiology, 34, 1-7. http://dx.doi.org/10.1159/000255459

[21] Downs, S.H. and Black, N. (1998) The Feasibility of Creating a Checklist for the Assessment of the Methodological Quality both of Randomised and Non-Randomised Studies of Health Care Interventions. Journal of Epidemiology \& Community Health, 52, 377-384. http://dx.doi.org/10.1136/jech.52.6.377

[22] Allcock, L.M., Kenny, R.A., Mosimann, U.P., Tordoff, S., Wesnes, K.A., Hildreth, A.J., et al. (2006) Orthostatic Hypotension in Parkinson's Disease: Association with Cognitive Decline? International Journal of Geriatric Psychiatry, 
21, 778-783. http://dx.doi.org/10.1002/gps.1562

[23] Idiaquez, J., Benarroch, E.E., Rosales, H., Milla, P. and Ríos, L. (2007) Autonomic and Cognitive Dysfunction in Parkinson's Disease. Clinical Autonomic Research, 17, 93-98. http://dx.doi.org/10.1007/s10286-007-0410-7

[24] Jones, J.D., Jacobson, C., Murphy, M., Price, C., Okun, M.S. and Bowers, D. (2014) Influence of Hypertension on Neurocognitive Domains in Nondemented Parkinson's Disease Patients. Parkinson's Disease, 2014, Article ID:507529. http://dx.doi.org/10.1155/2014/507529

[25] Kim, J.S., Oh, Y.S., Lee, K.S., Kim, Y.I., Yang, D.W. and Goldstein, D.S. (2012) Association of Cognitive Dysfunction with Neurocirculatory Abnormalities in Early Parkinson Disease. Neurology, 79, 1323-1331. http://dx.doi.org/10.1212/WNL.0b013e31826c1acd

[26] Nobili, F., Arnaldi, D., Campus, C., Ferrara, M., De Carli, F., Brugnolo, A., et al. (2011) Brain Perfusion Correlates of Cognitive and Nigrostriatal Functions in De Novo Parkinson's Disease. European Journal of Nuclear Medicine and Molecular Imaging, 38, 2209-2218. http://dx.doi.org/10.1007/s00259-011-1874-1

[27] Peralta, C., Stampfer-Kountchev, M., Karner, E., Köllensperger, M., Geser, F., Wolf, E., et al. (2007) Orthostatic Hypotension and Attention in Parkinson's Disease with and without Dementia. Journal of Neural Transmission, 114, 585588. http://dx.doi.org/10.1007/s00702-006-0615-2

[28] Pilleri, M., Facchini, S., Gasparoli, E., Biundo, R., Bernardi, L., Marchetti, M., et al. (2013) Cognitive and MRI Correlates of Orthostatic Hypotension in Parkinson's Disease. Journal of Neurology, 260, 253-259. http://dx.doi.org/10.1007/s00415-012-6627-y

[29] Nobili, F., Arnaldi, D., Campus, C., Ferrara, M., De Carli, F., Brugnolo, A., et al. (2011) Brain Perfusion Correlates of Cognitive and Nigrostriatal Functions in De Novo Parkinson's Disease. European Journal of Nuclear Medicine and Molecular Imaging, 38, 2209-2218. http://dx.doi.org/10.1007/s00259-011-1874-1

[30] Firbank, M.J., Colloby, S.J., Burn, D.J., McKeith, I.G. and O’Brien, J.T. (2003) Regional Cerebral Blood Flow in Parkinson's Disease with and without Dementia. Neuroimage, 20, 1309-1319. http://dx.doi.org/10.1016/S1053-8119(03)00364-1

[31] Van Laere, K., Santens, P., Bosman, T., De Reuck, J., Mortelmans, L. and Dierckx, R. (2004) Statistical Parametric Mapping of $(99 \mathrm{~m})$ Tc-ECD SPECT in Idiopathic Parkinson's Disease and Multiple System Atrophy with Predominant Parkinsonian Features: Correlation with Clinical Parameters. Journal of Nuclear Medicine, 45, 933-942.

[32] O’Donnell, J.P., Macgregor, L.A., Dabrowski, J.J., Oestreicher, J.M. and Romero, J.J. (1994) Construct Validity of Neuropsychological Tests of Conceptual and Attentional Abilities. Journal of Clinical Psychology, 50, 596-600. http://dx.doi.org/10.1002/1097-4679(199407)50:4<596::AID-JCLP2270500416>3.0.CO;2-S

[33] Golden, C.J. (1976) Identification of Brain Disorders by the Stroop Color and Word Test. Journal of Clinical Psychology, 32, 654-658. http://dx.doi.org/10.1002/1097-4679(197607)32:3<654::AID-JCLP2270320336>3.0.CO;2-Z

[34] Ruff, R.M., Light, R.H., Parker, S.B. and Levin, H.S. (1996) Benton Controlled Oral Word Association Test: Reliability and Updated Norms. Archives of Clinical Neuropsychology, 11, 329-338. http://dx.doi.org/10.1093/arclin/11.4.329

[35] Dubois, B., Slachevsky, A., Litvan, I. and Pillon, B. (2000) The FAB: A Frontal Assessment Battery at Bedside. Neurology, 55, 1621-1626. http://dx.doi.org/10.1212/WNL.55.11.1621

[36] Blessed, G., Tomlinson, B.E. and Roth, M. (1968) The Association between Quantitative Measures of Dementia and of Senile Change in the Cerebral Grey Matter of Elderly Subjects. The British Journal of Psychiatry, 114, 797-811. http://dx.doi.org/10.1192/bjp.114.512.797

[37] Alexopoulos, G.S., Abrams, R.C., Young, R.C. and Shamoian, C.A. (1988) Cornell Scale for Depression in Dementia. Biological Psychiatry, 23, 271-284. http://dx.doi.org/10.1016/0006-3223(88)90038-8

[38] Kelland, D.Z. and Lewis, R.F. (1996) The Digit Vigilance Test: Reliability, Validity, and Sensitivity to Diazepam. Archives of Clinical Neuropsychology, 11, 339-344. http://dx.doi.org/10.1093/arclin/11.4.339

[39] Robertson, I.H., Ward, T., Ridgeway, V. and Nimmo-Smith, I. (1996) The Structure of Normal Human Attention: The Test of Everyday Attention. Journal of the International Neuropsychological Society, 2, 525-534. http://dx.doi.org/10.1017/S1355617700001697

[40] Guidi, M., Paciaroni, L., Paolini, S., De Padova, S. and Scarpino, O. (2006) Differences and Similarities in the Neuropsychological Profile of Dementia with Lewy Bodies and Alzheimer's Disease in the Early Stage. Journal of the Neurological Sciences, 248, 120-123. http://dx.doi.org/10.1016/j.jns.2006.05.017

[41] Nobili, F., Brugnolo, A., Calvini, P., Copello, F., De Leo, C., Girtler, N., et al. (2005) Resting SPECT-Neuropsychology Correlation in Very Mild Alzheimer's Disease. Clinical Neurophysiology, 116, 364-375. http://dx.doi.org/10.1016/j.clinph.2004.09.001

[42] Desgranges, B., Baron, J.C., de la Sayette, V., Petit-Taboue, M.C., Benali, K., Landeau, B., et al. (1998) The Neural Substrates of Memory Systems Impairment in Alzheimer's Disease: A PET Study of Resting Brain Glucose Utilization. 
Brain, 121, 611-631. http://dx.doi.org/10.1093/brain/121.4.611

[43] Shapiro, A.M., Benedict, R.H., Schretlen, D. and Brandt, J. (1999) Construct and Concurrent Validity of the Hopkins Verbal Learning Test-Revised. The Clinical Neuropsychologist, 13, 348-358. http://dx.doi.org/10.1076/clin.13.3.348.1749

[44] Abikoff, H., Alvir, J., Hong, G., Sukoff, R., Orazio, J., Solomon, S., et al. (1987) Logical Memory Subtest of the Wechsler Memory Scale: Age and Education Norms and Alternate-Form Reliability of Two Scoring Systems. Journal of Clinical and Experimental Neuropsychology, 9, 435-448. http://dx.doi.org/10.1080/01688638708405063

[45] Mungas, D. (1983) Differential Clinical Sensitivity of Specific Parameters of the Rey Auditory-Verbal Learning Test. Journal of Consulting and Clinical Psychology, 51, 848-855. http://dx.doi.org/10.1037/0022-006X.51.6.848

[46] Aschenbrenner, S., Tucha, O. and Lange, K.W. (2000) Regensburger Wortflüssigkeits-Test: RWT. Hogrefe, Verlag für Psychologie, Göttingen.

[47] Wesnes, K.A. (2008) Assessing Change in Cognitive Function in Dementia: The Relative Utilities of the Alzheimer's Disease Assessment Scale-Cognitive Subscale and the Cognitive Drug Research System. Neurodegenerative Diseases, 5, 261-263. http://dx.doi.org/10.1159/000113719

[48] Fastenau, P.S., Denburg, N.L. and Hufford, B.J. (1999) Adult Norms for the Rey-Osterrieth Complex Figure Test and for Supplemental Recognition and Matching Trials from the Extended Complex Figure Test. The Clinical Neuropsychologist, 13, 30-47. http://dx.doi.org/10.1076/clin.13.1.30.1976

[49] Kessels, R.P., van Zandvoort, M.J., Postma, A., Kappelle, L.J. and de Haan, E.H. (2000) The Corsi Block-Tapping Task: Standardization and Normative Data. Applied Neuropsychology, 7, 252-258. http://dx.doi.org/10.1207/S15324826AN0704_8

[50] Dubois, B., Burn, D., Goetz, C., Aarsland, D., Brown, R.G., Broe, G.A., et al. (2007) Diagnostic Procedures for Parkinson's Disease Dementia: Recommendations from the Movement Disorder Society Task Force. Movement Disorders, 22, 2314-2324. http://dx.doi.org/10.1002/mds.21844

[51] Derejko, M., Slawek, J., Wieczorek, D., Brockhuis, B., Dubaniewicz, M. and Lass, P. (2006) Regional Cerebral Blood Flow in Parkinson's Disease as an Indicator of Cognitive Impairment. Nuclear Medicine Communications, 27, 945-951. http://dx.doi.org/10.1097/01.mnm.0000243370.18883.62

[52] Sambati, L., Calandra-Buonaura, G., Poda, R., Guaraldi, P. and Cortelli, P. (2014) Orthostatic Hypotension and Cognitive Impairment: A Dangerous Association? Neurological Sciences, 35, 951-957. http://dx.doi.org/10.1007/s10072-014-1686-8

[53] Senard, J., Brefel-Courbon, C., Rascol, O. and Montastruc, J. (2001) Orthostatic Hypotension in Patients with Parkinson's Disease: Pathophysiology and Management. Drugs \& Aging, 18, 495-505. http://dx.doi.org/10.2165/00002512-200118070-00003

[54] Nutt, J.G. (1987) On-Off Phenomenon: Relation to Levodopa Pharmacokinetics and Pharmacodynamics. Annals of Neurology, 22, 535-540. http://dx.doi.org/10.1002/ana.410220415

[55] Calne, D.B., Brennan, J., Spiers, A.S. and Stern, G.M. (1970) Hypotension Caused by L-Dopa. British Medical Journal, 1, 474-475. http://dx.doi.org/10.1136/bmj.1.5694.474

[56] Critchley, H.D., Mathias, C.J., Josephs, O., O’Doherty, J., Zanini, S., Dewar, B.K., et al. (2003) Human Cingulate Cortex and Autonomic Control: Converging Neuroimaging and Clinical Evidence. Brain, 126, 2139-2152. http://dx.doi.org/10.1093/brain/awg216

[57] Perry, R.H., Irving, D., Blessed, G., Fairbairn, A. and Perry, E.K. (1990) Senile Dementia of Lewy Body Type: A Clinically and Neuropathologically Distinct form of Lewy Body Dementia in the Elderly. Journal of the Neurological Sciences, 95, 119-139. http://dx.doi.org/10.1016/0022-510X(90)90236-G

[58] Quinn, N. (1995) Parkinsonism—Recognition and Differential Diagnosis. British Medical Journal, 310, 447-452. http://dx.doi.org/10.1136/bmj.310.6977.447

[59] Burdick, D.J., Cholerton, B., Watson, G., Siderowf, A., Trojanowski, J.Q., Weintraub, D., et al. (2014) People with Parkinson's Disease and Normal MMSE Score Have a Broad Range of Cognitive Performance. Movement Disorders, 29, 1258-1264. http://dx.doi.org/10.1002/mds.25924

[60] Hohler, A.D., Amariei, D.E., Katz, D.I., De Piero, T.J., Allen, V.B., Boyle, S., et al. (2012) Treating Orthostatic Hypotension in Patients with Parkinson's Disease and Atypical Parkinsonism Improves Function. Journal of Parkinson's Disease, 2, 235-240.

[61] Ridgel, A.L., Kim, C.H., Fickes, E.J., Muller, M.D. and Alberts, J.L. (2011) Changes in Executive Function after Acute Bouts of Passive Cycling in Parkinson's Disease. Journal of Aging and Physical Activity, 19, 87-98.

[62] Tanaka, K., Quadros Jr., A.C., Santos, R.F., Stella, F., Gobbi, L.T. and Gobbi, S. (2009) Benefits of Physical Exercise on Executive Functions in Older People with Parkinson's Disease. Brain and Cognition, 69, 435-441. 
http://dx.doi.org/10.1016/j.bandc.2008.09.008

[63] Berg, E.A. (1948) A Simple Objective Technique for Measuring Flexibility in Thinking. The Journal of General Psychology, 39, 15-22. http://dx.doi.org/10.1080/00221309.1948.9918159 


\section{Appendix A-Database Search Results}

\section{Scopus, PubMed, CINAHL, and citations from selected articles Scopus}

Search terms: autonomic [Ti, Ab, keyword], cognitive [TI], cardiovascular [TI, AB, keywords] (54) autonomic [Ti, Ab, keyword], cognitive [TI], Parkinson [TI, AB, keywords] (29)

PubMed

Search terms: ((cerebrovascular) and Parkinson's Disease) and Cognitive (175)

cerebrovascular* [TI/AB] or hypoperfusion* [TI, AB] and Parkinson's [TI, AB] and cognition* (body) (39)

cognition and hypoferfusion and autonomic (17)

"blood pressure" * (TI/AB) and cognitive* (TI/AB) and Parkinson's (TI/AB) (18)

Cardiovascular cognitive parkinsons (65)

CINAHL

Search Terms: autonomic* [TI, AB] and cognitive*[TI, AB] and Parkinson's [keyword] (15)

autonomic* [TI, AB] and cognitive* [TI, AB] (10)

autonomic [TI] and Parkinson's [TI] (10)

From Idiaquez, J., Benarroch, E.E., Rosales, H., Milla, P. and Rios, L. (2007) Autonomic and Cognitive Dysfunction in Parkinson's Disease. Clinical Autonomic Research, 17, 93-98.

http://dx.doi.org/10.1007/s10286-007-0410-7

Goldstein, M.A. and Silverman, M.E. (2006) Autonomics and Cognition. Clinical Autonomic Research, 16, 8689.

From Ridgel, A.L., Kim, C.H., Fickes, E.J., Muller, M.D. and Alberts, J.L. (2011) Changes in Executive Function after Acute Bouts of Passive Cycling in Parkinson's Disease. Journal of Aging and Physical Activity, 19, 87-98.

Tanaka, K., Quadros Jr., A.C., Santos, R.F., Stella, F., Gobbi, L.T. and Gobbi, S. (2009) Benefits of Physical Exercise on Executive Functions in Older People with Parkinson's Disease. Brain and Cognition, 69, 435-441. http://dx.doi.org/10.1016/j.bandc.2008.09.008

From "Related citations in PubMed" when searching Slobodin, T.N. (2012) Importance of Vascular Factors for Cognitive Rehabilitation in Parkinson's Disease Patients. Likars' ka sprava/Ministerstvo okhorony zdorov'ia Ukrainy, 7, 176-179.

Szirmai, I. and Kovacs, T. (2002) Parkinson Syndrome and Cognitive Disorders. Deggyogyaszati Szemle, 55, 220-225.

\section{Appendix B}

Common abbreviations

PD: Parkinson's Disease;

QOL: Quality of life;

CI: Cognitive impairment;

SPECT: Single photon emission computed tomography;

$\mathrm{OH}$ : Orthostatic hypotension;

HTN: Hypertension;

PDD: Parkinson's disease dementia;

MMSE: Mini-mental state exam;

BP: Blood pressure;

SH: Supine hypertension;

UPDRS: Unified Parkinson's disease rating scale;

L-dopa: Levodopa;

LBD: Lewy body disease. 